\title{
Paolo Valvo, Pio XI e la Cristiada. Fede, guerra e diplomazia in Messico (1926-1929), Brescia, Morcelliana, 2016.
}

El libro, de 540 páginas, viene a llenar un vacío de la historiografía sobre el conflicto entre la Iglesia católica y el Estado mexicano en la primera mitad del siglo XX, a saber, el seguimiento que se le dio a esta situación por parte de la Santa Sede, conocido en esta obra principalmente a través de la documentación de esos años, puesta a disposición de los investigadores del Archivo Secreto Vaticano apenas a partir del año 2006, con lo que se entiende que es la primera obra de gran calado que contempla dicha información, aunque no únicamente utiliza este archivo, sino también otros importantes para su fin, como el Archivo Romano de la Compañía de Jesús y el Archivo Histórico de la Arquidiócesis de México.

Paolo Valvo, conocido ya por sus investigaciones en torno a la anexión de Austria por el régimen nazi, así como por varios artículos escritos en torno a las relaciones Estado-Iglesia católica en México y otros países, se basó para la escritura de este libro en la consulta de numerosos archivos que, junto con periódicos y una extensa bibliografía, dieron como resultado esta obra que excede los límites de su título para darnos una visión general de la historia de México en la primera mitad del siglo XX, si bien centrada en el conflicto religioso, tanto en el análisis de la tensión entre el Estado y los católicos a causa de las disposiciones legales promovidas por el régimen revolucionario, como en el de los problemas suscitados al interior de la jerarquía católica por los diferentes puntos de vista de los obispos sobre la manera en que debían ser afrontados los inconvenientes que se iban suscitando.

La gran cantidad de informes y cartas que cita, echa por tierra la idea sostenida por algunos, de que la Santa Sede no estuvo suficientemente enterada de lo que sucedía en México. El estilo, en algunos casos detectivesco, permite al lector rastrear, junto con el autor, todas las pistas que llevan a la explicación de por qué se dieron ciertos acontecimientos. Si bien para quien no es aficionado a una investigación a fondo de los hechos puede resultar cansada la lectura, para el historiador, siempre ávido de llegar hasta las últimas consecuencias, las continuas citas textuales de los más de dos mil documentos a los que hace referencia constituyen un verdadero paseo a través de archivos que quizá nunca llegarán a pasar por sus manos.

Secuencia, e-ISSN 2395-8464 
La obra se divide en cinco capítulos, de los cuales solamente el tercero y el cuarto se circunscriben a los hechos de 1926-1929 que se anuncian en el título y que efectivamente son la parte central. Las claves para la lectura pueden ser muy diferentes, aunque en ningún caso corresponderán a la historia oficial de ninguna de las partes: ni buenos, ni malos; ni enemigos, ni amigos de la civilización y el progreso unos u otros. Una de estas claves que se puede seguir en buena parte de la obra es la de la intransigencia que se daba en ambas partes: «la prudencia no es una virtud común aquí en México», escribía el delegado apostólico Ernesto Filippi al cardenal secretario de Estado del Vaticano Pietro Gasparri unos meses antes de ser expulsado del territorio mexicano (p. 107). Y, en esta misma línea, afirmaba lapidariamente Tito Crespi, secretario de la nunciatura en México, un poco antes de que se agravara la crisis: "Se me perdone la audacia de decirlo pero, mientras no cambie el ambiente moral, político y eclesiástico de esta nación, el delegado de la Santa Sede solamente podrá sobrevivir aquí si poseyendo todas las cualidades que la Santa Sede exige a sus representantes en el extranjero, posee también las de ser sordo, mudo y ciego” (pp. 137-138).

Esta última opinión va en la línea de otras por el estilo en la que los informantes italianos de la Santa Sede solían expresar una postura bastante crítica sobre el modo de actuar no solo de los gobernantes, que en ese momento limitaban la actuación de la Iglesia católica, sino sobre todo de los dirigentes de esta, especialmente al arzobispo de México, José Mora y del Río, por no acatar frecuentemente las líneas de moderación y prudencia que intentaba imponer Roma. Fue precisamente después de sus funerales en San Antonio Texas en abril de 1928, cuando convocados por el obispo de Morelia se reunieron la mayor parte de los obispos mexicanos desterrados en los Estados Unidos y estuvieron de acuerdo en entablar negociaciones con el gobierno en las que no necesariamente se pusiera, como condición para reanudar el culto, la derogación de las leyes antirreligiosas y la reforma de algunos artículos constitucionales en que se fundaban (pp. 340-342).

Aunque el mismo Valvo lo había tratado en un par de artículos publicados anteriormente, no deja de ser interesante y novedoso conocer la parte final de las negociaciones entre los obispos Leopoldo Ruiz y Flores y Pascual Díaz Barreto con el presidente Emilio Portes Gil en las que una traducción deficiente de un telegrama recibido por los obispos con indicaciones de la Santa Sede facilitó que se aceptaran unas condiciones, de parte del gobierno, que no eran las que Roma estaba dispuesta a suscribir (pp. 430-436). 
El intrincado papel que tuvo que jugar la diplomacia vaticana, con el gobierno de México, con la jerarquía, con la Liga Nacional Defensora de la Libertad Religiosa, con los jesuitas, con la delegación apostólica en los Estados Unidos, con el gobierno mismo de ese país e, incluso, con otros gobiernos extranjeros, es otra de las aportaciones novedosas que plantea esta obra, en la que se ve, dentro del pontificado de Pío XI, un auténtico cambio de ritmo en la Secretaría de Estado luego del relevo del cardenal Pietro Gasparri por el también cardenal Pacelli, quien posteriormente se convertiría en Pío XII.

Como a cualquier obra escrita por un extranjero, se le puede reprochar, en algunos momentos, pequeñas faltas de conocimiento de la realidad nacional, como cuando presupone que Agustín Legorreta, director del Banco Nacional de México, era un funcionario de la administración del presidente Calles (p. 234). Sin embargo, la mayor carencia de esta obra estriba en que por el momento se encuentre solamente en italiano y que los lectores que no entiendan esta lengua tendrán todavía que esperar a que se traduzca.

Juan González Morfín

Universidad Panamericana, México gonzalezjuan1964@gmail.com 